\title{
$13 q$ deletion syndrome resulting from balanced chromosomal rearrangement in father: the significance of parental karyotyping
}

Sabine Dittner-Moormann ${ }^{1 *}$, Madlen Reschke ${ }^{2}$, Eva Biewald ${ }^{3}$, Alma Kuechler ${ }^{4}$, Barbara Klein ${ }^{5}$, Beate Timmermann ${ }^{6}$, Dietmar Lohmann ${ }^{4}$, Petra Ketteler ${ }^{1 \dagger}$ and Deniz Kanber ${ }^{4 \dagger}$

\begin{abstract}
Background: Retinoblastoma is a malignancy of the eye in children characterized by biallelic inactivation of the retinoblastoma 1 gene (RB1), located at chromosome 13q14.2. Children with interstitial chromosome 13q deletions that include the RB1 gene show a predisposition to develop retinoblastoma and variable other features. Large $13 q$ deletions with severe clinical phenotype are nearly always the result of a de novo mutation, i.e. the pathogenic alteration is not detected in parents. This results in a low risk for siblings to develop 13q deletion syndrome.

Result: Here, we describe a patient with profound muscle hypotonia, severe developmental delay and bilateral retinoblastoma carrying a large deletion in $13 q 13.3 q 14$ with the size of $16 \mathrm{Mb}$, involving the RB1 gene. Neither parent showed retinoblastoma, muscle hypotonia or developmental delay. Chromosome analysis and Fluorescence in situ hybridization (FISH) showed a balanced complex chromosomal rearrangement (CCR) between chromosome 12 and 13 [ins(12;13)(q21.2; q12.3q14.3)] and an additional balanced translocation of chromosome 7 and 15 [t(7; 15)(q31.2;q25.3)] in the healthy father. Malsegregation of the paternal insertional translocation involving chromosome 12 and 13 resulted in a 13q deletion syndrome of the child [46,XY,ins(12;13)(q21.2;q12.3q14.3)].

Conclusion: Balanced translocations in parents are a rare cause of de novo RB1 deletions in offspring. This case report emphasizes the need for parental chromosomal analysis and FISH in parents of children diagnosed with $13 q$ deletion syndrome or large RB1 gene deletions to precisely determine the recurrence risk in siblings. Guidelines for genetic testing should be revised accordingly.
\end{abstract}

Keywords: Retinoblastoma, 13q deletion, Complex chromosomal rearrangement, Balanced translocation

\footnotetext{
* Correspondence: Sabine.Dittner-Moormann@uk-essen.de

†Petra Ketteler and Deniz Kanber contributed equally to this work and share last authorship.

'Department of Pediatric Hematology and Oncology, University Hospital Essen, Hufelandstraße 55, 45147 Essen, Germany

Full list of author information is available at the end of the article
}

(c) The Author(s). 2020 Open Access This article is licensed under a Creative Commons Attribution 4.0 International License, which permits use, sharing, adaptation, distribution and reproduction in any medium or format, as long as you give appropriate credit to the original author(s) and the source, provide a link to the Creative Commons licence, and indicate if changes were made. The images or other third party material in this article are included in the article's Creative Commons licence, unless indicated otherwise in a credit line to the material. If material is not included in the article's Creative Commons licence and your intended use is not permitted by statutory regulation or exceeds the permitted use, you will need to obtain permission directly from the copyright holder. To view a copy of this licence, visit http://creativecommons.org/licenses/by/4.0/. The Creative Commons Public Domain Dedication waiver (http://creativecommons.org/publicdomain/zero/1.0/) applies to the data made available in this article, unless otherwise stated in a credit line to the data. 


\section{Background}

Retinoblastoma $(\mathrm{Rb})$ is a rare cancer, but the most common malignant neoplasm of the eye in children. The estimated global incidence is $1 / 15,000$ to $1 / 20,000$ live births [1]. In about $60 \%$ of all patients with $\mathrm{Rb}$ the tumor affects only one eye (unilateral $\mathrm{Rb}$ ), usually with a single tumor focus. Both eyes are affected in $40 \%$ of patients with $\mathrm{Rb}$ (bilateral $\mathrm{Rb}$ ), mostly with multiple tumor foci. $\mathrm{Rb}$ occurs almost exclusively in children under the age of 5 years. In Germany, the median age at diagnosis is 24 months for the unilateral, unifocal type and $<12$ months for bilateral $\mathrm{Rb}$ [2].

$\mathrm{Rb}$ arises from retinal cone cell progenitors that have lost normal function of the retinoblastoma protein $(\mathrm{pRb})$ as a consequence of genetic alterations of both alleles of the $R B 1$ gene. Patients with heritable $R b$ are heterozygous for a variant allele of the $R B 1$ gene (first mutation) and usually develop $\mathrm{Rb}$ in both eyes (bilateral $\mathrm{Rb}$ ). In most patients with bilateral $\mathrm{Rb}$ this variant allele is the result of a de novo mutation in the germline of a parent. Development of $\mathrm{Rb}$ is triggered by a second mutational event that occurs in somatic cells and results in alteration or loss of the other allele. Patients with heritable $\mathrm{Rb}$ have a high risk of developing further non ophthalmologic tumors [3]. In non-heritable $\mathrm{Rb}$ presenting mostly as unilateral unifocal tumor both $R B 1$ alleles are altered as result of mutations in somatic cells.

Patients with deletions on chromosome $13 \mathrm{q}$ show variable clinical features and a high risk of $\mathrm{Rb}$ if the $R B 1$ gene is involved. Chromosome 13 is the largest acrocentric human chromosome, bearing one of the lowest gene densities (6.5 genes per $\mathrm{Mb}$ ) [4]. The association of mental and growth retardation with $\mathrm{Rb}$ was first described as an entity in 1969 [5]. Additional characteristics in patients with $13 \mathrm{q}$ deletion syndrome include moderate to severe mental retardation or psychomotor delay, muscular hypotonia, seizures, growth delay, craniofacial dysmorphic features and various congenital defects of the brain, eye, gastrointestinal tract, urogenital tract, kidney and heart $[6,7]$. Size and location of chromosome 13q deletion affects clinical phenotype and the occurrence of $\mathrm{Rb}[7,8]$. Deletion of a chromosomal segment can occur de novo or can be inherited due to parental chromosomal aberration [7, 9].

\section{Material and methods}

Methylation-specific multiplex ligation-dependent probe amplification (MS-MLPA)

For methylation and dosage analysis of the $R B 1$ region MS-MLPA (MRC Holland, SALSA MLPA probemix P047-D1 RB1) was performed according to the manufacturer's protocol.
Cytogenetic and molecular cytogenetic analysis

Cytogenetic analysis was performed on GTG banded metaphase chromosomes from PHA stimulated blood lymphocytes [10]. The same metaphase preparations were also used for molecular cytogenetic analysis (FISH) which was performed according to standard procedures based on the manufacturer's protocol. Following commercially available probes were used: whole chromosome painting probe wcp 12, MetaSystems, XCP12 Orange, Cat.No. D0312-050-OR; wcp 13, MetaSystems, XCP13 Green, Cat.No. D-0313-050-FI; RB1, Abbott, Vysis LSI 13 RB1 (13q14) SpectrumOrange Probe, Cat.No. 08 L65-020. Images were captured on Zeiss Axioplan microscope (Zeiss Jena, Germany) with IKAROS and ISIS digital fluorescence in situ hybridization (FISH) imaging system (MetaSystems, Altlussheim, Germany).

\section{Case presentation}

\section{Clinical report}

The male patient was born spontaneously at $38+5$ weeks of gestation after an uneventful pregnancy to healthy nonconsanguineous parents with unremarkable family history. Birthweight was $2610 \mathrm{~g}$ (3rd percentile, 1.9 SDS), length $48 \mathrm{~cm}$ (5th percentile, $-1.6 \mathrm{SDS}$ ), head circumference $35 \mathrm{~cm}$ (44th percentile, - 0.14 SDS) [11], Apgar score 10/10. Muscular hypotonia was noticed postpartum. Cerebral ultrasound at 6 days of life showed slightly asymmetric lateral ventricles (right > left) but otherwise normal results. Screening by automated auditory brainstem response was normal. The patient showed craniofacial dysmorphism including a high forehead and deep-set ears. Developmental delay of motor function and speech were first diagnosed at the age of 11 months. Electroencephalography showed inconspicuous results. At the age of 22 months motor skills equaled those of a 7 month old. At the age of 3 years, the patient had made slight progress on his motor skills but not on language development.

Examination of the cardiovascular system including electrocardiogram and echocardiography showed normal results.

At the age of 9 months the parents observed leukocoria. At the age of 1 year bilateral Rb was diagnosed according to international classification of retinoblastoma (ICRB) and international retinoblastoma staging system (IRSS). The right eye was classified as ICRB E, IRSS I and the left eye as ICRB D, IRSS 0 . The right eye was enucleated due to advanced tumor stage with signs for infiltration of the optic nerve on MRI scan. Histopathological examination of the enucleated right eye confirmed focal choroidal and intralaminar optic nerve infiltration.

The intensive eye-preserving treatment using chemotherapy and percutaneous proton beam radiotherapy for 
the remaining eye failed after multiple relapses. The second eye had to be enucleated 6 months after diagnosis. At that time ophthalmologic examination revealed no light perception, vision non lux. Histopathological examination of the eye showed neither choroidal, scleral nor optic nerve infiltration nor infiltration of the anterior segment.

During chemotherapy, the patient developed mild hearing impairment of the right ear (about $30 \mathrm{~dB}$ at $2-4 \mathrm{kHz}$ ).

\section{Genetic testing}

After counselling and obtaining informed consent from the parents, molecular genetic testing was performed. Testing started with Multiplex Ligation-dependent Probe Amplification (MLPA) on DNA from blood, because syndromic features of the patient suggested a contiguous gene deletion syndrome including the $R B 1$ gene. Results of MLPA which included analysis of dosage and methylation showed a hemizygous deletion of the $13 \mathrm{q} 13.3 \mathrm{q} 14.3$ region $(16.6 \mathrm{Mb})$ including the $R B 1$ gene. Hypermethylation at CpG85 on the remaining allele, a characteristic feature of the maternal allele, suggested that the deleted allele is of paternal origin.

Paternal chromosomal analysis revealed balanced complex chromosomal rearrangement with a reciprocal translocation between long arms of chromosome 7 and 15 with breakpoints located at 7q31.2 and $15 \mathrm{q} 25.3$ and an insertional translocation involving chromosome 12 and 13 [46,XY,ins(12;13)(q21.2;q12.3q14.3)].

Aberration of chromosome 12 and 13 is an insertion of a short segment of chromosome 13 into the long arm of chromosome 12 at $12 \mathrm{q} 21.2$. This inserted fragment, 13q12.3q14.3, contained the $R B 1$-locus as confirmed by FISH analysis (Fig. 1).

\section{Discussion and conclusion}

This case report describes a patient with heritable retinoblastoma predisposition caused by a large deletion on chromosome 13q that arose on the basis of a balanced chromosomal rearrangement in the father.

Most 13q deletion syndromes are reported to occur de novo and, given the paucity of published cases it appears that cases similar to the one reported here are rare $[9$, $12,13]$. Strong et al. characterized a family in which 10 cases of unilateral $\mathrm{Rb}$ occurred over four generations transmitted by eight unaffected individuals. Chromosomal analysis of four living $\mathrm{Rb}$ patients revealed an interstitial deletion of the long arm of chromosome 13, $\operatorname{del}(13)$ (q13.1q14.5). Clinical characteristics of all Rb patients in the family included failure to thrive, developmental delay and mild to severe mental retardation. Retrospectively, these symptoms would be classified as part of $13 q$ deletion syndrome. Chromosome analysis of all transmitting family members who were alive showed balanced karyotype with insertional translocation of the deleted chromosome 13 into the short arm of chromosome 13. Further eight individuals in this family showed an unbalanced triplication of the $13 q(q 13.1 q 14.5)$ segment, but this alteration was not associated with any specific clinical phenotype [14].

Another reported case of deletion of a $13 q$ segment derived from a familial 12;13 insertional translocation. The phenotype was concordant with that expected of an interstitial deletion including the $R B 1$ locus: bilateral $\mathrm{Rb}$,

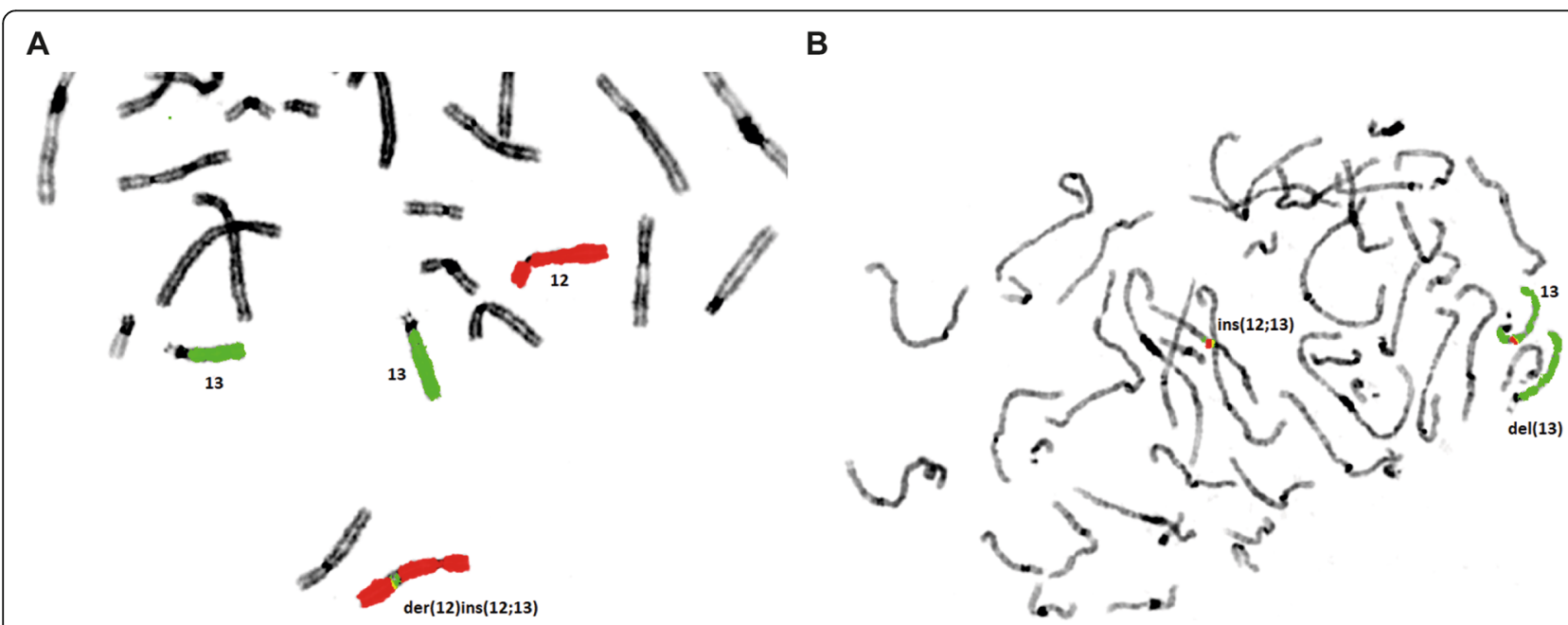

Fig. 1 Balanced complex chromosomal rearrangement between chromosome 12 and 13 detected by FISH analysis on metaphase chromosomes of the patient's father. a FISH with whole chromosome paint (wcp) probes for chromosome 12 (red) and 13 (green) reveals a signal for the probe wcp 13 (green) on one chromosome 12. Thus, the derivative chromosome 12 has an insertion of material from chromosome 13

(der(12)ins(12;13)). b The inserted Region contains the RB1 gene. The probe for $R B 1$ (red) provides a signal on the derivative chromosome 12 and a signal on one of the chromosomes 13 (wcp 13, green) - no signal for RB1 on del(13) 
severe psychomotor retardation, failure to thrive, dysmorphic facial features, anomalous pinnae, accessory nipples, cryptorchidism, abnormal foot posturing and diffuse myocardial hypertrophy with disrupted fibre muscle orientation. Mother and grandmother carried the balanced insertional translocation. In one sibling of the patient the $13 \mathrm{q}$ chromosomal segment was triplicated. In line with the report of Strong et al. the phenotypic consequences appeared to be relatively modest [15].

Current suggestions for best practice of genetic testing in unaffected parents of patients with large $R B 1$ gene deletions include deletion testing but do not require chromosome analysis or other methods to detect balanced alterations in patient and parents [16]. This recommendation reflects that at least among published findings balanced alterations in a parent appear to be a rare cause of $R B 1$ gene deletions in children. Both previous reports $[14,15]$ were published at a time when cytogenetic analysis was the first line analysis for genetic testing in retinoblastoma. Today, molecular methods of deletion testing are favored over cytogenetic analysis. Moleculargenetic methods are not expected to detect balanced translocations and this may lead to an underestimation of the frequency of such alterations.

Genetic testing in parents is frequently motivated by the question of recurrence risk in future siblings. Current molecular methods such as MLPA will detect heterozygous or high level mosaic deletions, but balanced parental chromosomal alterations escape detection by molecular methods such as MLPA or array analysis. However, balanced alterations result in recurrence risk for siblings of up to $50 \%$. The frequencies of submicroscopic insertional translocations as cause of apparent de novo chromosomal aberrations has been reported as high as $2 \%$ [17]. This reported frequency and the high recurrence risk in siblings warrants parental chromosome and FISH analysis as part of the clinical routine testing in all families with interstitial aberrations and therefore also in parents of children with 13q deletion syndrome. Detection of potential progenitors of $R B 1$ gene deletions are important for genetic counselling of the family and may warrant testing of further family members. On the ground of the presented findings cytogenetic analysis including FISH for the RB1 locus in children with $13 q$ deletion syndrome and in their parents are strongly recommended along with molecular genetic array diagnostics of large chromosomal aberrations. Only the combination of molecular and cytogenetic testing will provide high quality of genetic counselling and avoids the case of a present balanced chromosomal alteration in a parent being undetected.

\section{Abbreviations}

CCR: Complex chromosomal rearrangement; FISH: Fluorescence in situ hybridization; ICRB: International classification of retinoblastoma;
IRSS: International retinoblastoma staging system; MLPA: Multiplex Ligationdependent Probe Amplification; MRI: Magnetic Resonance Imaging; Rb: Retinoblastoma; RB1: Retinoblastoma 1 gene

\section{Acknowledgements \\ Not applicable.}

\section{Authors' contributions}

$\mathrm{MR}, \mathrm{BK}, \mathrm{PK}, \mathrm{EB}, \mathrm{BT}, \mathrm{SDM}, \mathrm{DK}$ and $\mathrm{AK}$ did the data acquisition. Quality control of data and algorithms was done by SDM, DK and PK. SDM, DK, PK and DL did the data analysis and interpretation. SDM, DK, PK and DL prepared the manuscript. Manuscript editing was done by SDM, DK and PK. Manuscript review was done by all authors. The author(s) read and approved the final manuscript.

\section{Funding}

The Deutsche Kinderkrebsstiftung (Grant number DKS 2016.09) financed this study. Open access funding provided by Projekt DEAL.

\section{Availability of data and materials}

The datasets used and/or analyzed during the current study are available from the corresponding author on reasonable request.

\section{Ethics approval and consent to participate}

Genetic counselling was performed before and after genetic testing. Written informed consent for publication of this case was obtained from the patient's parents.

\section{Competing interests}

The authors declare no conflict of interest.

\section{Author details}

${ }^{1}$ Department of Pediatric Hematology and Oncology, University Hospital Essen, Hufelandstraße 55, 45147 Essen, Germany. ${ }^{2}$ Department of Pediatric Hematology, Oncology and Stem Cell Transplantation, Charité -

Universitätsmedizin Berlin, Berlin, Germany. ${ }^{3}$ Department of Ophthalmology, University Hospital Essen, Essen, Germany. ${ }^{4}$ Institute of Human Genetics, University Hospital Essen, Essen, Germany. ${ }^{5}$ Sozialpädiatrisches Zentrum, Klinikum Frankfurt Höchst GmbH, Frankfurt a. M, Germany. ${ }^{6}$ Department of Particle Therapy, West German Proton Therapy Centre Essen (WPE), West German Cancer Center (WTZ), German Cancer Consortium (DKTK), University Hospital Essen, Essen, Germany.

Received: 6 May 2020 Accepted: 30 June 2020

Published online: 23 July 2020

\section{References}

1. Fabian ID, Onadim Z, Karaa E, Duncan C, Chowdhury T, Scheimberg I, et al. The management of retinoblastoma. Oncogene. 2018;37(12):1551-60.

2. Temming P, Viehmann A, Biewald E, Lohmann DR. Sporadic unilateral retinoblastoma or first sign of bilateral disease? Br J Ophthalmol. 2013;97(4): 475-80.

3. Temming P, Arendt M, Viehmann A, Eisele L, Le Guin CH, Schundeln MM, et al. Incidence of second cancers after radiotherapy and systemic chemotherapy in heritable retinoblastoma survivors: a report from the German reference center. Pediatr Blood Cancer. 2017;64(1):71-80.

4. Dunham A, Matthews LH, Burton J, Ashurst JL, Howe KL, Ashcroft KJ, et al. The DNA sequence and analysis of human chromosome 13. Nature. 2004; 428(6982):522-8.

5. Allderdice PW, Davis JG, Miller OJ, Klinger HP, Warburton D, Miller DA, et al. The 13q-deletion syndrome. Am J Hum Genet. 1969;21(5):499-512.

6. Wang YP, Wang DJ, Niu ZB, Cui WT. Chromosome 13q deletion syndrome involving 13q31qter: a case report. Mol Med Rep. 2017;15(6):3658-64.

7. Mitter D, Ullmann R, Muradyan A, Klein-Hitpass L, Kanber D, Ounap K, et al. Genotype-phenotype correlations in patients with retinoblastoma and interstitial 13q deletions. Eur J Hum Genet. 2011;19(9):947-58.

8. Dehainault C, Garancher A, Castera L, Cassoux N, Aerts I, Doz F, et al. The survival gene MED4 explains low penetrance retinoblastoma in patients with large RB1 deletion. Hum Mol Genet. 2014;23(19):5243-50. 
9. Rapini N, Lidano R, Pietrosanti S, Vitiello G, Grimaldi C, Postorivo D, et al. De novo 13q13.3-21.31 deletion involving RB1 gene in a patient with hemangioendothelioma of the liver. Ital J Pediatr. 2014;40:5.

10. Verma RSBA. Human chromosomes - manual of basic technologies: Pergamon press; 1989.

11. Fenton TR, Kim JH. A systematic review and meta-analysis to revise the Fenton growth chart for preterm infants. BMC Pediatr. 2013;13:59.

12. Tosca L, Brisset S, Petit FM, Metay C, Latour S, Lautier B, et al. Genotypephenotype correlation in 13q13.3-q21.3 deletion. Eur J Med Genet. 2011 54(5):e489-94.

13. Brown S, Gersen S, Anyane-Yeboa K, Warburton D. Preliminary definition of a "critical region" of chromosome 13 in q32: report of 14 cases with 13q deletions and review of the literature. Am J Med Genet. 1993;45(1):52-9.

14. Strong LC, Riccardi VM, Ferrell RE, Sparkes RS. Familial retinoblastoma and chromosome 13 deletion transmitted via an insertional translocation. Science. 1981;213(4515):1501-3.

15. Riccardi VM, Hittner HM, Francke U, Pippin S, Holmquist GP, Kretzer F, Ferrell R. Partial triplication and deletion of 139: Study of a family presenting with bilateral retinoblastoma. Clin Genet. 1979;15:332-45.

16. Lohmann DR, Gallie BL. Retinoblastoma: revisiting the model prototype of inherited cancer. Am J Med Genet C Semin Med Genet. 2004;129c(1):23-8

17. Nowakowska BA, de Leeuw N, Ruivenkamp CA, Sikkema-Raddatz B, Crolla $J A$, Thoelen $R$, et al. Parental insertional balanced translocations are an important cause of apparently de novo CNVs in patients with developmental anomalies. Eur J Hum Genet. 2012;20(2):166-70.

\section{Publisher's Note}

Springer Nature remains neutral with regard to jurisdictional claims in published maps and institutional affiliations.

Ready to submit your research? Choose BMC and benefit from:

- fast, convenient online submission

- thorough peer review by experienced researchers in your field

- rapid publication on acceptance

- support for research data, including large and complex data types

- gold Open Access which fosters wider collaboration and increased citations

- maximum visibility for your research: over $100 \mathrm{M}$ website views per year

At $\mathrm{BMC}$, research is always in progress.

Learn more biomedcentral.com/submissions 